\title{
Circulating Libraries and Video Rental Stores
}

\author{
Richard Roehl \\ Hal R. Varian* \\ University of Michigan, Dearborn \\ University of California, Berkeley \\ December 1996 \\ Revised: March 9, 2000
}

\begin{abstract}
We describe a number of interesting parallels between circulating libraries in England circa 1725-1850 and video rental stores in the U.S. circa 1980-1990. Both institutions evolved in a similar manner, which suggests that common economic and social forces were at work. Perhaps the histories of these two industries may be helpful in understanding current and future developments in computer- and Internet-related media.
\end{abstract}

According to Loomis [1994], p. 608, “... the history of libraries, particularly in the United States and Great Britain, during the 18th and much of 19th centuries is dominated by subscription libraries." He distinguishes three types of subscription libraries: book clubs, private subscription libraries, and commercial circulating libraries. Book clubs were essentially discussion groups and did not maintain permanent collections. Private subscription libraries were primarily the "... purview of an affluent minority" that "attempted to collect standard works of permanent value in history, biography, travel,

* Research support from NSF grants 9320481 and 9979852 and is gratefully acknowledged. We also thank Michael Buckland, David Mitch, and Joel Mokyr for providing helpful comments and references. Email for comments: hal@sims.berkeley.edu, rroehl@umich.edu. 
and natural science." Circulating libraries, the chief concern of this paper, were profit-seeking enterprises, and were specifically targeted to appeal to the popular taste.

The economic history of circulating libraries in Britain is remarkably similar to the history of video stores in the US two hundred years later. Both institutions were profit-seeking rental libraries designed to appeal to the mass market. This similarity of function led to similarities in the development of their business models, the structure of their industry, and their relationship with providers of complementary products.

\section{Growth of the rental market for books}

In the early 1720 s there were a few booksellers that also advertised booksfor-hire in London. Loomis [1994], p. 609, indicates that the first circulating library specifically created for rental was started by the bookseller Allan Ramsay in Edinburgh in 1725. By 1740-50 there were at least nine such circulating libraries in London. This number grew to nineteen between 177080 and to twenty-six from 1790-1800. (Hamlyn [1946]) estimated there were "not less than one thousand" circulating libraries in England by 1850, many of which were located in spas and other vacation spots. (Hamlyn [1946], p. 198.)

\section{Growth of the rental market for videos}

After the VCR was first introduced as a consumer item, it was viewed as a device for "time shifting" television shows to more convenient viewing hours. However, it subsequently became clear that there was significant market demand for pre-recorded videos. The first company to sell pre-recorded videos was Andre Blay's Video Club of America. He acquired fifty titles from Twentieth Century Fox studios that had all been previously sold to network TV. At the time of his first ad (in an October 1977 issue of TV Guide), there were fewer than 200,000 VCR owners, but more than 9,000 of them joined Blay's video club.

By December of that year competition between RCA and Sony had pushed video machine prices to below $\$ 1,000$ for the first time. By the end

of March 1978 Blay had sold 40,000 cassettes, and by the end of the year he 
had sold over 250,000.

While Blay explored the video sale market, the first individual to see the possibilities for a video rental market was one George Atkinson who ran a "Mickey Mouse little business" in Los Angeles called Home Theater Systems. Atkinson rented Super Eight film projectors, screens and old movies for $\$ 25$ a night. He bought one Beta and one VHS copy of each of the fifty Fox titles sold by Blay. In order to raise capital quickly he charged fifty dollars for an annual membership and one hundred dollars for a "life membership." Members could rent videos for $\$ 10$ a day. (Lardner [1987], pp. 176-7)

Atkinson encountered many skeptics. Most studio executives thought that American audiences preferred to buy rather than rent. At the time, video machines were a luxury that were only affordable by the wealthy who could easily afford to buy videos at the approximately $\$ 50$ price that was then charged. Since the video machine was widely expected to remain a luxury item, most Hollywood executives did not anticipate the emergence of a mass rental market. Atkinson's great insight was that that video machines would continue to decline in price and become a mass market item ... and middle class users would prefer renting a video at $\$ 3$ to buying one at $\$ 50$.

\section{Why they grew}

The primarily trade of the circulating libraries was renting light fiction. The motivation for the circulating library was the same as that of the video store: affordability. The early editions of Tom Jones cost more than an ordinary worker's weekly wage. Middle class people would not pay for novels, but they would happily rent them. According to McKillop [1934], the primary stimulus for the growth of circulating libraries was that the "increasing demand for light reading forced the adoption of some new device for rapid circulation." Circulating libraries provided this new economic model in the latter half of the eighteenth century, just as video rental stores provided a new economic model two hundred years later.

According to Plant [1974] "[During the sixteenth and seventeenth centuries] the reader had to rely on his own private library and those of his friends" since there were no public libraries. Most of the works available in private libraries were on serious topics such as religion, law, and the classics. A library of forty works or so was substantial." (Plant [1974], pp. 263-64)

The circulating libraries changed all this. By 1761 it was noted that "the 
reading female hires her novels from some country Circulating Library, which consists of about a hundred volumes." (Plant [1974], p. 264)

As in the case of video rental stores, the bookrenters originally "... hoped to protect themselves by requiring an initial deposit large enough to forestall any possible loss ... [but] ... competition soon forced the librarians to give up the hope of extracting a substantial deposit." (McKillop [1934], p. 482)

Both circulating libraries and video stores explored a variety of pricing options. Some of the early circulating libraries had various classes of membership that allowed different numbers of books to be taken out for different lengths of time. Similarly video stores experimented with a variety of pricing plans: prepayment, volume discounts (or surcharges), membership classes, and so on. However, each industry eventually settled on a similar economic model: they required membership in order to track customers, but the membership fee was nominal or non-existent. The primary revenue flow was from rental fees for the merchandise.

\section{Role of erotic content}

The growth of circulating libraries in England is intimately related to the growth of the novel. Ian Watt's celebrated study of the rise of the novel makes the interesting point that one reason for the novel's popularity is that it could appeal to the prurient interest in ways that were unavailable via other "respectable" (or even not so respectable) media:

"But the supreme reason for Richardson's dependence on the novel's mode of performance is, of course, his concern with that most private aspect of experience, the sexual life. The stage, in Western Europe at least, has never been able to go very far in the description of sexual behavior, whereas in his novels Richardson was able to present much that in any other form would have been quite unacceptable to an audience whose public demeanor, at least, was very severely controlled by the intensified taboos of a Puritan morality." (Watt [1957], p 199)

The situation with videos was similar: a significant fraction of the early video rental business consisted of erotic material. Estimates in 1978-79 indicate that $75 \%$ of all pre-recorded tapes sold were X-rated. (Anonymous [1980]) According to observers, "early VCR adopters had private and, for 
the first time, ready access to intriguing, yet socially unacceptable material." (Levy [1989], p. 31) Just as the early readers of the novel found its depiction of erotic material in the privacy of their own home appealing, so too did early adopters of videos.

Of course, as the industry grew, "adult" themes became less dominant. By 1980, 37\% of the pre-recorded videos were X-rated, and by 1981 the fraction fell to $33 \%$. Still, there was a considerable demand for this material. Since the cost of producing videos was substantially less than that of film production, a large industry emerged to satisfy the demand. ${ }^{1}$

It was the same with novels. In fact, English authors could not keep up with the demand for racy novels and the English public turned to expert purveyors of this material: the French. "Literary historians have more than once remarked on the apparent connection between the success of Pamela and the rapid growth of the circulating libraries of London .... in the years immediately following Pamela the staple works of the circulating libraries were largely translated from the French." (McKillop [1934], 484-85.)

According to Hamlyn [1946], p. 218, one guide to running a circulating library indicated that out of 1,500 books, 1050 should be novels and 130 romances, making 80 percent of the books fiction. ${ }^{2}$

Three of the most well-known early English novels, Pamela, Tom Jones, and Moll Flanders had explicitly risqué themes. Other novels were less racy, but romantic themes predominated. According to Watt [1957], p. 43, many of the readers of the early novels were women. Watt goes on to quote Coleridge's views on the merits of novels:

"As to the devotees of the circulating libraries, I dare not compliment their pass-time or rather kill-time with the name of reading. Call it rather a sort of beggardly day-dreaming, during which the mind of the dreamer furnishes for itself nothing but laziness and a little mawkish sensibility."

Sounds almost as bad as television, doesn't it? Certainly one can find many examples of film, video and television productions that were similarly

\footnotetext{
${ }^{1}$ We have seen a similar pattern with DVD. According to Nichols [1999], “ [www.dvdreview.com] lists roughly 6,000 titles. About 1,800 of them are sexually oriented films, a category that is flourishing on DVD as it did on tape in the early days of video."

${ }^{2}$ It is interesting to note that in modern times about $70 \%$ of the books lent by public libraries in England are fiction. (Anonymous [1995], p. 85).
} 
denounced in the twentieth century. But as Plant [1974] explains, "Even the Puritanical disapproval of light literature could not altogether destroy the craving for romance."

\section{$5 \quad$ Inventory policy}

In the early days of both video stores and circulating libraries, when owners of the establishment relied on membership fees for capital, the surest way to attract members was to have a large inventory. According to a pioneer in the rental business, "having a large [video] library sets you apart from the other people in the neighborhood who don't ... they're more likely to join the club with the more movies." (Lardner [1987]). A common strategy of the pioneer video stores was to plow membership fees back into inventory enlargement.

The same was true for circulating libraries. Hamlyn [1946] describes one that advertised 100,000 volumes in 1787 . It is notable that the figure comes from an advertisement - which presumably means that the proprietor thought that his inventory was a significant attraction to potential customers.

However, there were competing forces. In the movie rental business "about twenty percent of your movies do about eighty percent of your profit." (Lardner [1987], 182.) The most reliable demand in both movies and novels was the demand for the hot items of the day; the large inventory served the viewers and readers who had exhausted the current items of interest.

In both industries this led to the policy of purchasing a substantial number of the current hot sellers which were rented out for short periods of times. Once the initial demand was exhausted, old copies were sold in the "previously viewed" bin, and a few were retained for inventory.

The consequence is that used books (and videos) were widely available at attractive prices, which created a base for home libraries in each medium. The desire for ownership, which was once discouraged by high prices, began to resurface once the used merchandise was offered at affordable prices. (We return to this point in section 9.)

\section{Forces behind growth of book rental}

Videos and books both require an initial investment in order to "view" them. Video cassettes require a video machine and books require knowing how to 
read. Literacy and books had to grow in parallel, just as the market for VCRs and pre-recorded videos grew in parallel.

Examining the book market first, it is important to recognize the purely economic barrier facing readers. Books were a luxury item in the 1500s: "The purchasers of book, however, in the fifteenth and sixteenth centuries were almost wholly confined to the class of nobles and those of the richer citizens and scholars by profession. It was a very long time before the influence of the press had produced any direct effect upon the habits of the great mass of people." Knight [1854], 250.

As we noted above,

"Tom Jones cost more than a laborour's average weekly wage. It is certain, therefore, that the novel's audience was not drawn from such as wide cross-section of society as, for example, that of Elizabethan drama. All but the destitute had been able to afford a penny occasional to stand in the pit of the Globe; it was no more than the price of a quart of ale. The price of a novel, on the other hand, would feed a family for a week or two." (Watt [1957], 42)

Watt goes on to note that:

"The extent to which economic factors retarded the expansion of the reading public, and especially that for the novel, is suggested by the rapid success of the non-proprietary or circulating libraries, as they were called after 1742 when the term was invented ... Subscriptions were moderate: the usual charge was between half a guinea and a guinea a year, and there were often facilities for borrowing books at the rate of a penny a volume or threepence for the usual three-volume novel.

Most circulating libraries stocked all types of literature, but novels were widely regarded as their main attraction; and there can be little doubt that they led to the most notable increase in the reading public for fiction which occurred during the century. They certainly provoked the greatest volume of contemporary comment about the spread of reading to the lower orders. These 'slop-shops in literature' were said to have debauched the minds of schoolboys, ploughboys, 'servant women of the better sort' and 
even of 'every butcher and baker, cobbler and tinker throughout the three kingdoms'. It is likely therefore, that until 1740 a substantial marginal section of the reading public was held back from a full participation in the literary scene by the high price of books; and further, that this marginal section was largely composed of potential novel readers, many of them women." (42-43)

According to Knight [1854], p. 313, there were 80,000 readers in England in 1800. He claims that by 1854 there were 140,000 buyers of cheap weekly sheets and probably 5 million readers. During this 50 -year period, the number of readers increased by a factor of 60 ! Knight is not clear about his definition of what constitutes a "reader," or how he came up with these estimates. It appears that he is refering to "frequent reader" rather than a narrow definition of literacy.

But even narrow measures of literacy tell a similar story. According to Cipolla [1969], p. $68-69$, in 1755 only about $50 \%$ of the those contracted to marriage outside of London were able to sign their names. By 1800 this figure had grown to $54 \%$. But by 1850 , the literacy rate, by this definition, was $65-70 \%$. We see almost a $\% 50$ increase in 50 years.

The demand for reading material prior to 1800 was satisfied by newspapers, literary periodicals, and books, in that order. In 1724 in London there were 3 daily papers, 7 which were published 3 times a week, and 6 weekly papers. The circulation of these newspapers was in the thousands. Books were a distant third in terms of sales.

But, "In spite of the low general level of education, there was evidently by this time a good potential demand for reading-matter if only the bookseller could offer the right material. It was his business to forecast what this right material would be. He was on fairly safe ground where the newest form of literature, the novel, was concerned ... As novels increased in number so did the new circulating libraries, and, a point of the first importance to the book trade, the reading habit spread to women." (Plant [1974], p. 57)

Plant suggests that the reason that there were so few readers prior to 1800 was that there wasn't much interesting to read. Since books were so expensive they were only available to the very wealthy. Daily and weekly newspapers were concerned primarily with politics and business. Women, who were precluded from participation in political and business life, were, for this reason, likely not to have much interest in newspapers. Novels were much more attractive since they were concerned with universal themes-life 

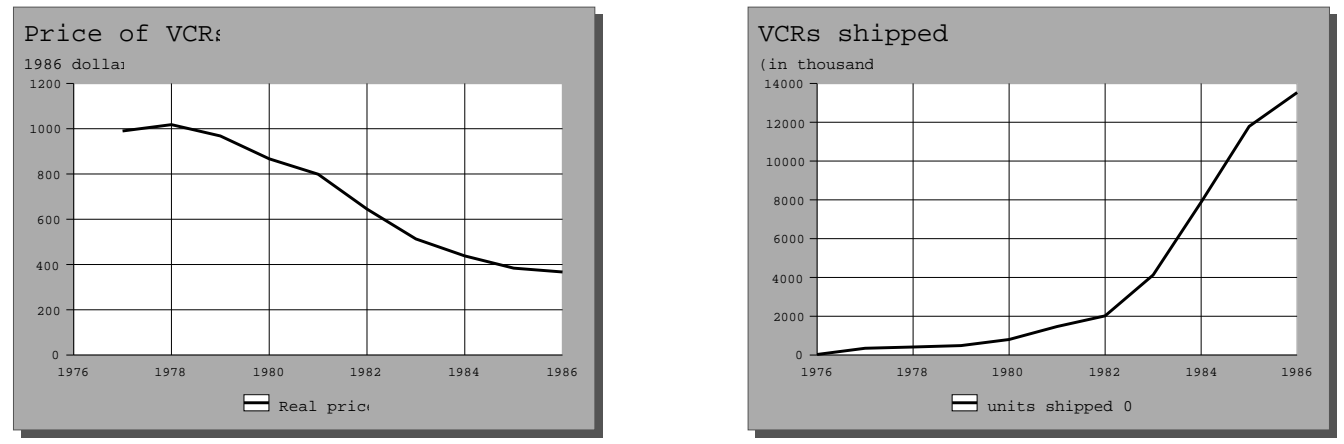

Figure 1: VCR prices and units shipped.

and love, rather than politics and business.

\section{$7 \quad$ Forces behind growth of video rental}

As we mentioned in section 6, there is a chicken-and-egg problem in both the book and video industries. Consumers didn't want to invest in facility with reading unless they had access to cheap literature, and the market wouldn't provide cheap literature without assurances it would be purchased. Similarly, customers didn't want to rent a video unless they had a video player, and they didn't want to buy a video player unless they had ready access to content. We've seen how this problem was overcome in the rental book market; in this section we examine the video rental market.

Figure 1 depicts the price and units shipped of video machines from the late nineteen seventies until the early eighties. At the start of the decade, video machines cost around $\$ 1,000$ and were primarily toys for the wealthy; by the end of the decade they were mass market consumer items.

There was a standalone use of video recorders that made them attractive purchases even without a video tape market, namely, time shifting of TV programs. Early in the eighties, time shifting was the predominant use of VCRs, but by the end of the decade, pre-recorded videos were substantial. This is shown clearly in Figure 2, which depicts the shipments of blank and pre-recorded video tapes. In 1979 there were nearly 4 blank tapes shipped for every pre-recorded one; by 1992, the ratio was about 1:1. 

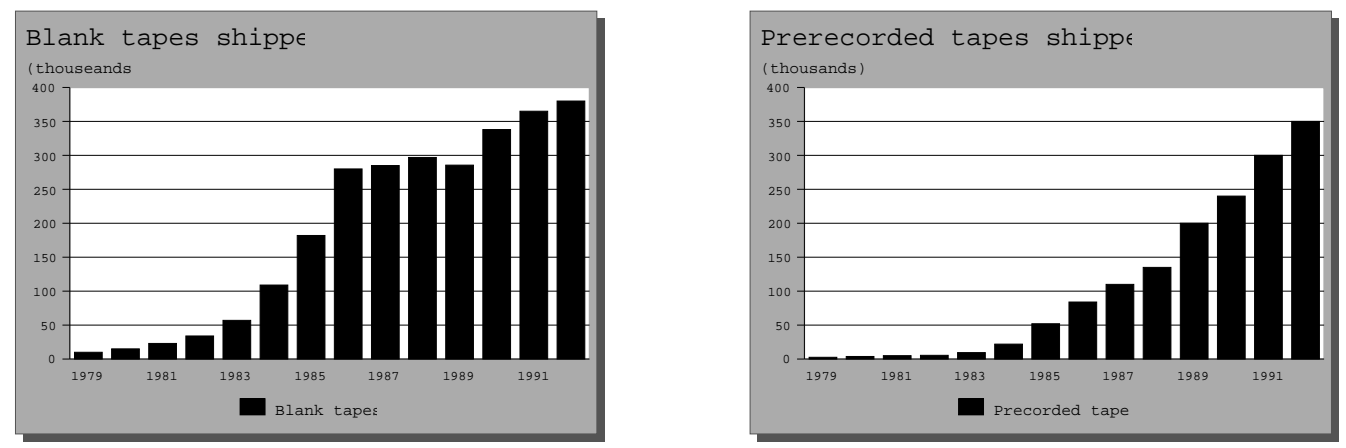

Figure 2: Blank and pre-recorded video tapes shipped.

Video stores also developed the policy of renting video players along with the cassettes. A common practice in the mid-eighties was to rent a video machine plus some tapes for a child's birthday party or just a weekend of viewing. This allowed the video stores to create a demand for their primary product; as prices of video machines declined, customers purchased their own machines, and video rental stores could focus on their primary business.

Although circulating libraries were not able to "rent" readers, there was a related phenomenon. During this period it was very common to read aloud, and mothers or fathers reading to their children (or their spouses) was not uncommon. In fact, it appears that vocalized reading (as opposed to silent reading) was the norm for most of the population. Boswell, for example, noted with surprise that Johnson could read without moving his lips.

To the modern reader, this appears very strange, but in an era where literacy and books were both rare, reading aloud to an audience was highly efficient and no doubt strongly encouraged. There was little reason to develop the skill of silent reading.

\section{Backlash from the producers}

The publishers were not enthused about the growth of circulating libraries:

"In the 'Life of Lackington' there is the following passage:- "I have been informed that, when circulating libraries were first 
opened, the booksellers were much alarmed; and their rapid increase added to their fears, and led them to think that the sale of books would be much diminished by such libraries. But experience has proved that the sale of books, so far from being diminished by them, has been greatly promoted; as from these repositories many thousand families have been cheaply supplied with books, by which the taste of reading has become more general, and thousand of books are purchased each year by such as have first borrowed them at those libraries, and after reading, approving of them, have become purchasers." Knight [1854], p. 234 (also quoted by Plant [1974], p. 265).

Just as publishers were initially leery of book rentals, so were Hollywood studios leery of the home video market. Movie studios tried on several occasions to curb the growth of video rental. Studios wanted to ban rentals entirely, but the "first-sale doctrine" indicates that the first purchaser can do what he wants with a piece of intellectual property, so there was no legal ground to prohibit video rental. ${ }^{3}$

Subsequently the studios tried to modify license arrangements in order to price discriminate between videos sold to end users and those sold to rental outlets. Paramount added a "surcharge" of $\$ 1$ to $\$ 10$ to their cassette price. Walt Disney productions offered a 12-week rental license that allowed retailers to rent cassettes however often they liked at whatever price they could get.

In 1981 a video rental executive said "The studios want total control of the cassette from the manufacturer to the customer. The odds for success are fairly low, but in an attempt to do that we'll see constant revisions of rental schemes and another couple of years of turmoil." (Leff [1981]).

This forecast was partially correct: the studios tried to control the rental market but failed. By 1983 most of the studios had given up on licensing schemes and were relying on selling tapes to both rental stores and end users at the same price. As in the case of books, the Hollywood producers were lucky that they failed in controlling the growth of the rental market, for it was that very growth that led to their subsequent success.

\footnotetext{
${ }^{3}$ Interestingly enough, producers of music CDs were able to prohibit the rental of CDs in the mid-eighties by arguing rental outlets would facilitate the production of exact digital copies.
} 


\section{Growth of video purchase}

The video market took an interesting turn in the mid-eighties. The widespread availability of rental outlets induced millions of consumers to take the plunge and buy VCRs. (See Figure 1 above, and note the significant upturn in 1982.) The ready availability of these home units then stimulated a latent demand for ownership, at least for some sorts of videos.

The first firm to really exploit this demand was Walt Disney Productions with their release of Lady and the Tramp in 1987 at $\$ 29.95$. By 1988, they had sold 3.2 million copies which made this the best-seller up to that time. However, they were soon eclipsed by $E T$ which sold roughly 14 million copies (at $\$ 19.95$ apiece) by 1993 .

By the early 90s, the purchase market became a significant factor for video stores. In 1992 consumers spent an estimated $\$ 9$ billion on video rentals and $\$ 4$ billion on video purchases.

The market soon developed into two segments: some videos targeted for the rental market had a retail price of $\$ 80-\$ 90$ and a wholesale price of about $\$ 60$. Videos targeted for consumer purchase were priced at $\$ 19.95$ and below for the sales market. The sales market generally consisted of children's videos, a market in which repeat viewing is rampant. According to a 1991 article, "videos aimed at children account for at least half of the best sellers in any given week. [In 1990] children's videos made up about $37 \%$ of all videos sold," according to Blumenthal [1991].

Varian [1995] presents an economic model whether to price cassettes for purchase or for rental. He identifies transactions costs, desire for repeated view, and market segmentation as important issues in making the sell v. rent pricing decision, and describes industry pricing practices. The same pricing considerations must have confronted the publishers of the nineteenth century, but we have little data or evidence on which to base an analysis.

During this same period, the video market changed from a "mom-andpop" industry to one dominated by a few large firms. According to the Wall Street Journal, "the principal villain is price competition." According to industry observers, a medium-sized independent had a breakeven price of about $\$ 3.95$ per night, but competition had pushed prices to $\$ 2$ a night and less in many areas.

By 1993, the industry was dominated by large chains. The biggest of these, Blockbuster, had close to 2,000 U.S. outlets and controlled about $15 \%$ of the rental market. The second-biggest chain was probably West Coast 
Video with roughly 500 outlets. Anonymous [1993].

In 1991 the Wall Street Journal indicated that "video sales are booming" (Grossman [1991], p. B1). According to the Journal the video market had matured with the $\$ 8$ billion rental market slowing to less than $4 \%$ annual growth per year. At the same time the $\$ 3$ billion sales market was growing at $10 \%$ to $15 \%$ per year. The big sellers were children's videos, classic films, and special-interest tapes (news, cooking, exercise, and so on). In 1991 the prices of many videos were at the $\$ 14.95$ range. McDonalds sold 5-6 million copies of Indiana Jones for $\$ 5.99$. Gasoline stations and supermarkets also did extensive promotions involving videos.

By 1996, consumers spent $\$ 9.2$ billion on rental and $\$ 7.3$ billion on purchase of videos. The average household with a VCR (roughly $85 \%$ of American households) purchased more than seven titles in 1996, up from six in 1995. The most recent phenomenon is the made-for-video, or home premiere business. Disney released one such video in each of 1994, 1995, and 1996 and released three such videos in 1997. The 1996 release, "Aladdin and the King of Thieves," had sales of over 10 million units and generated at least $\$ 130$ million in revenue. (Orwall [1997])

\section{Growth of book purchase}

Returning to the 18th century we can detect similar examples of price declines of books, though not of the same magnitude. As with video stores, the libraries grew out of the selling business and "the two branches of the business helped one another." (McKillop [1934] p. 218.) Furthermore, we noted above, books that went out of fashion were sold on the second-hand market, (McKillop [1934], p. 482), a practice also followed by video rental stores.

"I suppose that more than four times the number of books are sold now [c. 1850] than were sold twenty years since. The poorer sort of farmers, and even the poor country people in general, who before that period spent their winter evenings in relating stories of witches, ghosts, hobgoblins \&c now shorten the winter nights by hearing their sons and daughters read tales, romances, \&c and on entering their houses you may see Tom Jones, Roderick Random, and other entertaining books, stuck up on their baconracks, \&tc." (Plant [1974], p. 58). 
If we can take this quote at face value it appears that the trend in both the video stores and circulating libraries was much the same: the initial market for both items was available only to the rich. The development of the rental market helped to spread the material to the masses, and, at the same time stimulated the masses to acquire the necessary equipment and/or skills to take advantage of the availability of the materials. In the case of videos, this was the video machine itself; in the case of reading, it was the ability to read. In each case, the industry was driven by the availability of light reading/viewing, but the widespread literacy and light entertainment also laid the groundwork for more substantial material.

Once the equipment and/or skills were acquired, users demonstrated a desire for purchase, which was satisfied, initially, by used copies of previously popular works. But once this market grew large enough, publishers and producers were happy to sell to it.

The fact that the lower price of books brought with them a desire for ownership had a dampening effect on the circulating library business. By the early 1800s, bankruptcies of circulating libraries were not uncommon. According to McKillop [1934], p. 221, "The chief libraries to fail were, I suggest, the smaller ones run by inexperienced proprietors with little knowledge of the book trade."

This trend continued through the century.

"The late 19th century marked a period of decline for [circulating] libraries .... A growing and increasingly diverse reading public created a demand for books that the small, often homogeneous collections of the subscription libraries were unable to satisfy. This demand contributed to the establishment of taxsupported public library systems during the 1850s in both [the US and Great Britain]. While this posed little threat initially, as public libraries became more established toward the end of the century, many subscription and circulating libraries were unable to compete and their collections were either discarded or absorbed into those of the public libraries." (Loomis [1994], p. 610)

Circulating libraries persisted in England until after World War II. What finally did them in was a combination of competition from public libraries and the rise of the paperback book - an even more effective way of reaching the mass market. 


\section{Contracting issues in rental}

In 1998 Blockbuster Video, a large chain of video stores owned by Viacom, started to advertise "guaranteed in stock." This meant that if the video you wanted wasn't in stock, you would get a coupon for a free rental of it. Why did this promotion suddenly occur in 1998 ?

To understand this, we should look at the nature of the contractual agreements between the rental stores and the distributors of videos. After some experimentation in the mid-80s, described briefly in section 8, most studies settled down to charging a flat wholesale price of about $\$ 60$ for videos targeted for the rental market.

This is much higher than the marginal cost of production (which is about \$1) leading stores to economize on their purchase, which in turn caused inefficient queuing on the part of consumers. In early 1998 content providers came up with a different model. In one variation, the video store pays the studio a one-time fee of $\$ 2-\$ 4$ per videotape and then pays $40 \%$ of rental revenues. This earns the store a profit per rental of about $\$ 2.25$. (Figures taken from Said [1999].) With this sort of "sharecropping" arrangement, stores no longer have strong incentives to economize in video purchase, reducing the queuing for customers. In fact, this is the form of contract used in Blockbuster's "guaranteed in stock" promotion.

A very similar discussion of rental business models took place in England in the 1870s. The motivating issue was the high cost of books.

"Trevelyan agreed with other writers that if cheaper editions were published at the outset authors would find themselves equally well compensated by the royalties on the larger number which would be sold. As things were it seemed that the only way for bookbuyers to be served cheaply was for the bookseller to share with them part of the discount which he was allowed by the publisher. This in many cases he was willing to do, and during part of the nineteenth century was allowed to do; but at what cost of strife and argumentation we shall see later on." (Plant [1974], pp. 41617)

The "strife and argumentation" was due to the difficulty of monitoring such sharing arrangements. What is necessary is a low-cost, incorruptible accountant, who can note each sale and divide the proceeds accordingly. 
This was hard to find in 1870 , but by 1998 such monitors were commonly available in video stores in the form of computerized cash registers. Without such monitoring of rental revenues on a per video basis, it would be difficult to enforce contracts that depend on profit-sharing of the sort we have described. It was precisely these contracting difficulties that caused problems between the nineteenth-century English publishers and circulating libraries.

\section{Implications for the Internet}

In examining the video and book rental market we have seen several effects that appear to be taking place in the current development of the Internet and the World Wide Web. Certainly erotic material played a significant role in the early development of all three media. Just as the circulating library industry and the video rental industry searched for viable economic models, so too do the providers of Internet content. The demand for network access and the availability of online content go hand in hand today, just as literacy and books or video cassettes and video machines did previously.

Finally, there is the widespread fear among content providers that these new technologies will act to their detriment. Just as publishers feared circulating libraries and Hollywood feared video rental outlets, today's producers of digital content fear that the Internet will dilute the value of their intellectual property. Perhaps some dilution will occur, but the historical record seems to suggest that the expansion of the market may well outweigh the impact of this dilution.

Indeed we see this happening currently in the recorded music market. The availability of MP3 music files on the Internet at sites like www.mp3.com has inspired fear and loathing in the music industry. Their initial impulse was to suppress it via legal action. Their next impulse was to control it, via alternative licensing and copy-protection schemes. Both initiatives appear to have failed. At this point the industry is asking, with considerable trepidation: "How can we make money out of it?" The history of rental books and rental videos suggests that there is probably a business model for very low-cost music distributed over the Internet, just as there was for low-cost books and videos. 


\section{References}

Anonymous. Untitled. Merchandising, page 53, March 1980.

Anonymous. Industry surveys. Leisure Time, pages 25-27, March 111993.

Anonymous. Ravenous readers. The Economist, page 85, January 281995.

Karen Blumenthal. Children's tapes help the sales market grown up. Wall Street Journal, December 4:B1, 1991.

Carolo M. Cipolla. Literacy and Development in the West. Harmondsworth, Penguin, 1969.

Laurie M. Grossman. Entertainment: for video sales it's a green Christmas. Wall Street Journal, 1991.

Hilda M. Hamlyn. Eighteenth-century circulating libraries in England. The Library, pages 197-222, December 1946.

Charles Knight. The Old Printer and the Modern Press. John Murray, London, 1854.

James Lardner. Fast Forward. W. W. Norton \& Co., New York, 1987.

Laurel Leff. Firms renting videocassettes worry studios. Wall Street Journal, March 271981.

Mark R. Levy. The VCR Age. Sage, London, 1989.

Abigail A. Loomis. Subscription libraries. In Wayne A. Wiegand and Jr. Donald G. Davis, editors, Encyclopedia of Library History, pages 608-10. Garland Publishing, Inc., New York \& London, 1994.

Alan Donald McKillop. English circulating libraries, 1725-50. The Library, 14:477-485, March 1934.

Peter M. Nichols. Home video: Videodiscs make inroads. New York Times, November 121999.

Bruce Orwall. Video buying is surprise hit with viewers. Wall Street Journal, page B1, January 171997. 
Marjorie Plant. The English Book Trade. George Allen \& Unwin Ltd, London, 3rd edition, 1974.

Carolyn Said. Chips and flicks on your doorstep fast-growing Kozmo wants to be Net's video, convenience store. San Francisco Chronicle, October 18, 1999.

Hal R. Varian. Buying, renting, and sharing information goods. Technical report, School of Information Management and Systems, UC Berkeley, 1995.

Ian Watt. The Rise of the Novel. University of California Press, Berkeley, CA, 1957. 